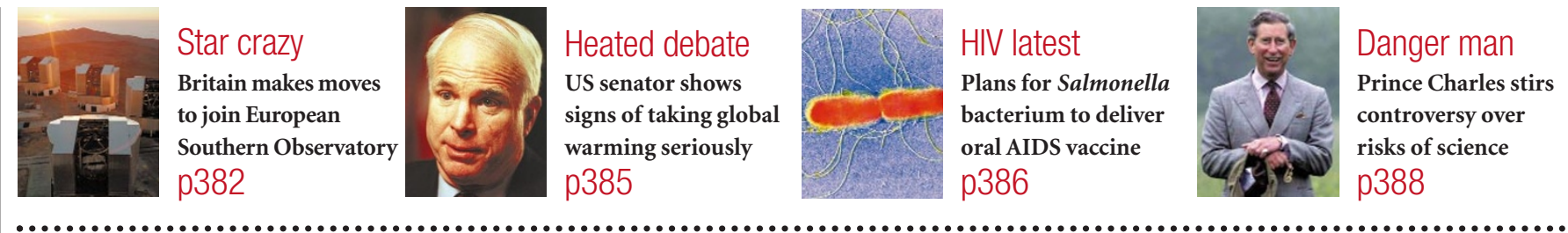

\title{
US astronomers draw up their wish list for a decade of funding
}

Tony Reichhardt, Washington

Bigger, better and a bit more expensive: that's the next generation of astronomical observatories envisaged by a panel of more than 100 scientists who last week laid out a ten-year road-map for US astronomy and astrophysics.

The planning exercise, organized once every decade by the National Academy of Sciences, is closely watched by government agencies that fund large astronomy facilities.

The 'decadal review' for 2000-10 was cochaired by Christopher McKee, a theoretical astrophysicist at the University of California, Berkeley, and Joseph Taylor of Princeton University, who shared a Nobel Prize for finding evidence of gravitational waves from a binary pulsar.

Formed in 1998, McKee and Taylor's committee and nine sub-panels spent nearly a year ranking priorities for the next decade of astronomical observation, both spacebased and ground-based.

Their top recommendation is the Next Generation Space Telescope (NGST), a \$1 billion successor to the Hubble Space Telescope. Orbiting a million miles from Earth, NGST will use an 8-metre deployable mirror to observe in the infrared, where it will see the oldest and faintest galaxies with hundreds of times the sensitivity of Hubble. The US space agency NASA, in cooperation with the European Space Agency and Canada, hopes to launch the NGST in 2009.

Second on the wish list is a 30 -metrediameter ground-based telescope known as the Giant Segmented Mirror Telescope (GSMT), which is similar in design to the current Keck telescopes in Hawaii but three times their size.

Just as Keck complements Hubble's highresolution images with high-resolution spectroscopy, the GSMT and NGST would give optical-infrared astronomers a powerful one-two punch for addressing problems ranging from the evolution of galaxies to the search for planets around other stars.

Several concepts have emerged recently for giant ground-based telescopes with apertures ranging in size from 30 to 100 metres. In recommending an instrument at the low

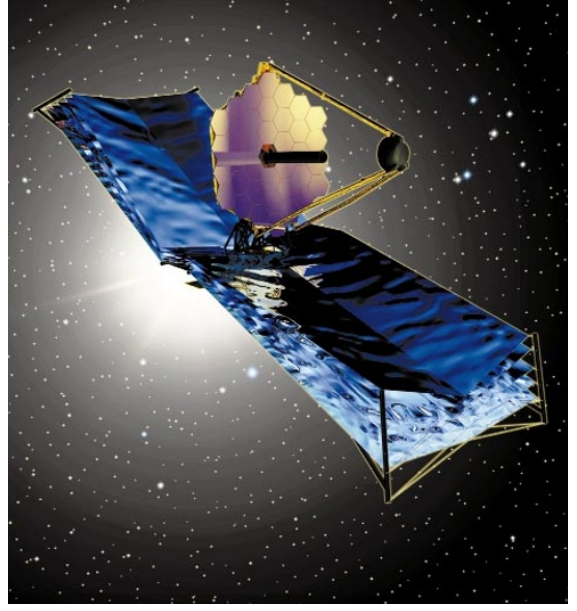

Top tip: the Next Generation Space Telescope is the advisory panel's number one priority.

end of that scale, the panel chose caution over performance.

"When we looked at the technology development for a 100-metre telescope, we got scared," says Taylor. Not that the GSMT couldn't eventually be reconciled with the 100-metre 'Overwhelmingly Large Telescope' (OWL) concept being studied by the European Southern Observatory, he says (see page 382). The panel recommends that half the GSMT's \$350 million cost come from either international or university partners.

Other major initiatives - defined as space facilities costing over $\$ 500$ million and ground-based projects over $\$ 50$ million are, in order of priority: the Constellation-X Observatory, a suite of four space-based telescopes that would succeed the current Chandra X-ray observatory and focus its investigations on black holes; an upgrade to the Very Large Array (VLA) of radio telescopes in New Mexico; and the Large-Aperture Synoptic Survey Telescope (LSST), a wide-field, fast-read-out telescope that could survey the entire visible sky down to faint objects at the 24th magnitude every week.

Formerly known as the 'Dark Matter Telescope', the LSST was renamed to better reflect the variety of subjects it will address, from cataloguing supernovae to finding

\section{France sets up élite Internet school}

\section{Heather McCabe, Paris}

France is to create a grande école - an élite higher-education institution - dedicated to the Internet, French Prime Minister Lionel Jospin announced last week. It will begin teaching courses in fields from computer science to electronic commerce next year.

The 'Grande École de l'Internet' will be near Marseilles - joining a 'technopole' of existing technology-orientated businesses and institutions. Its running costs, estimated at about FF60 million (US\$8.2 million) each year, will be shared by the government, the University of Aix-Marseille, two grandes écoles organizations - the Groupe des Écoles des Télécommunications (GET) and Les Écoles des Mines - and private industry.

One of the new institution's tasks is to redress the country's shortage of computer engineers - projected to reach 60,000 by 2005 , according to Claude Guéguen, the scientific director of GET. Jospin's research, technology and space adviser, Bertrand Mabille, says: "It's a real problem to find enough people to work in the industry, especially in start-up technology companies."

The two-year programme will be open to students who have completed master's-level work at engineering schools and universities, or who have completed their first year at a grande école of engineering.

Gilles Kahn, scientific director of INRIA, France's computing research agency, welcomes the new grande école, but says much more is needed.

"We can't content ourselves with creating this one institution," he says. "We must make efforts across the board to improve technology education." 
90 per cent of all near-Earth asteroids larger than 300 metres across.

The panel's highest-priority 'moderate' mission is not the most expensive on the list, but many astronomers consider the proposed $\$ 50$ million Telescope System Instrumentation Program to be vital to the health of their field. By funding new instruments for private telescopes such as the Keck, which is owned by California universities, the federal government will be buying a certain amount of access for all US astronomers.

Other moderate initiatives include the Gamma-ray Large Area Space Telescope (GLAST), which will succeed the Compton Gamma Ray Observatory; a pioneering gravity-wave telescope in space called LISA (for Laser Interferometer Space Antenna); an Advanced Solar Telescope; and - a rarity for astronomy - an instrument to be placed on the International Space Station, known as the Energetic X-ray Imaging Survey Telescope (EXIST).

The top 'small' initiative identified in the report is the National Virtual Observatory (NVO), a programme to compile astronomical data gathered in different wavelengths into a single large database accessible to scientists and the public. John Bahcall, an astrophysicist with the Princeton Institute for Advanced Study who led the last decadal review in 1991, likens the NVO to a hot "growth stock" on Wall Street. "Many of the most important discoveries will come from mining this database," he says.

The overall programme proposed by the McKee-Taylor panel would cost $\$ 4.7$ billion up to $2010-20$ per cent more than the wish list offered by Bahcall's committee ten years
Prioritized equipment initiatives and estimated federal costs, 2000-10

Initiative Cost $(\$$ million $)$

\section{Major initiatives}

Next Generation Space Telescope (NGST) $\quad 1,000$

Giant Segmented Mirror Telescope (GSMT) 350

Constellation-X Observatory $\quad 800$

Expanded Very Large Array (EVLA) $\quad 140$

Large-Aperture Synoptic Survey Telescope (LSST) 170

Terrestrial Planet Finder (TPF)

200

Single-Aperture Far InfraRed (SAFIR) Observatory 100

Moderate initiatives

Telescope System Instrumentation Program (TSIP) 50

Gamma-ray Large Area Space Telescope (GLAST) 300

Laser Interferometer Space Antenna (LISA) 250

Advanced Solar Telescope (AST) $\quad 60$

Square Kilometre Array (SKA) technology

development

Solar Dynamics Observer (SDO) 22

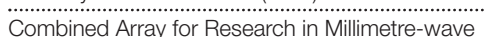

Astronomy (CARMA)

Energetic X-ray Imaging Survey Telescope (EXIST) 150

Very Energetic Radiation Imaging Telescope Array

System (VERITAS)

Advanced Radio Interferometry between Space

and Earth (ARISE)

35

Frequency Agile Solar Radiotelescope (FASR) 26

South Pole Submillimetre Telescope (SPST) $\quad 50$

Small initiatives

National Virtual Observatory (NVO)

Other small initiatives

Total for all initiatives

246

ago. Early in its deliberations, the committee asked NASA and the National Science Foundation, the two funding agencies responsible for most US astronomy, how fiscally conservative it should be, and were told "not to restrain ourselves", says Taylor.
If past decadal reviews are any guide, the new report should be well received on Capitol Hill and in the White House budget office. All four major initiatives proposed by Bahcall's committee in 1991 have since been approved, as have nine out of 11 moderatesize projects. Indeed, the astronomy surveys are almost unique in their influence on Washington decision-makers.

William Wulf, president of the National Academy of Engineering, believes the reason is that they "are not typical please-sendmoney reports — they represent some tough decisions".

Indeed, says Bahcall, the exercise is a "heart-wrenching" process in which astronomers "have to turn down proposals that were a decade in the making".

The committee also tried to consider input from the wider astronomical community, not just the élite, according to Lee Anne Willson, an astronomer at Iowa State University who chairs the astronomy section of the American Association for the Advancement of Science.

She set up a web page for rank-and-file astronomers to provide comments to the survey committee, and says that the comments were read. The committee's final decisions were also thoroughly vetted - after the sub-panels and panels did their work, another 23 readers weighed in with opinions as part of the National Research Council's review process.

The report probably comes as close to a consensus as it could, given the time it took to produce, says Willson. "Astronomy should be proud of itself."

http://books.nap.edu/catalog/9839.html

\section{Britain asks to join European Southern Observatory}

\section{David Dickson, London \& Alison Abbott, Munich}

Keen to see the creation of a single European body with the clout to raise the funds needed for future large telescopes, Britain is this week opening negotiations about possible membership of the European Southern Observatory (ESO).

Based in Munich, the eight-member ESO is responsible for the construction and operation of a number of telescopes in the Southern Hemisphere, notably the Very Large Telescope (VLT) currently being built on Mount Paranal in Chile.

Britain declined to join the organization when it was set up in 1962, claiming that it could not afford to do so. But Ian Halliday, the chief executive of the Particle Physics and Astronomy Research Council (PPARC), said last week that are now several reasons for becoming a member.

As well as giving British astronomers access to the VLT, membership of the ESO

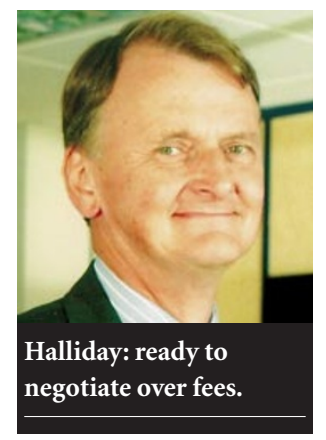

would allow the PPARC to become directly involved in the planning of major new international facilities, such as the proposed optical telescope known as the Overwhelmingly Large Telescope (OWL).

"In 10 years' time, if we want to build this type of facility, we need to be part of an organization such as ESO," says Halliday. "We will not be able to afford to build it ourselves."

Many members of the ESO, including its director Catherine Cesarsky, are happy for Britain to join. Franco Pacini, a member of the ESO council and director of the Arcetri
Astrophysics Observatory in Florence, says: "No-one would deny how important it will be for ESO to have Britain as a member. It is a pity that [Britain] did not join long ago."

But agreeing on the terms of entry will not be easy. The treaty setting up the ESO stipulates that new members must pay an entry fee as a contribution to the capital costs of the facilities they will be able to use.

In Britain's case, the entry fee would be $\mathfrak{E} 55$ million (US\$81.8 million). But Halliday says that, given the pressures on the UK science budget, paying such a sum is out of the question. "If they are insistent about us paying our full whack, we will not be able to get into ESO," he says.

One ESO official says: "It is an unfortunate moment [for Britain to ask for special treatment] because ESO has just made a huge investment in the VLT, and member states may not be too happy about 